\title{
FR-4 Substrate Based Modified Ultawideband Antenna with Gain Enhancement for Wireless Applications
}

\author{
K. G. Tan ${ }^{1}$, S. Ahmed ${ }^{1, *}$, Abdelsalam Hamdi ${ }^{1}$, C. X. Ming ${ }^{1}$, K. Abdulwasie ${ }^{1}$, Ferdous \\ Hossain $^{1}$, Choo-Peng ${ }^{1}$, H. Basarudin ${ }^{2}$, Mohd Khairil Rahmat ${ }^{2}$ and Vinesh Thiruchelvam ${ }^{3}$ \\ ${ }^{I}$ Multimedia University, Faculty of Engineering and Technology, 75450 Melaka, Malaysia \\ ${ }^{2}$ UniKL British Malaysia Institute, Selangor, Malaysia \\ ${ }^{3}$ Asia Pacific University of Technology \& Innovation, Kuala Lumpur 57000, Malaysia
}

Received 17 December 2018; Accepted 27 August 2019

\begin{abstract}
A new circular shape patch ultrawideband (UWB) single feed microstrip antenna is described in this paper. The radiated patch of the proposed UWB antenna is embedded with slots to improve the radiation characteristics ensuring a wide impedance bandwidth. In the ground plane, two rectangular rings slots are etched to provide proper impedance matching over a wide frequency range. The proposed single layer UWB with overall dimensions of $55 \mathrm{~mm}$ by $56 \mathrm{~mm}$ is fabricated using low cost 4.3 relative permittivity FR-4 substrate. From results obtained, the antenna can provide an impedance bandwidth ranging from $2.2 \mathrm{GHz}$ to more than $12 \mathrm{GHz}(138 \%)$ that is wider than the standard UWB band. In addition, the modified UWB antenna can enhance the gain to more than $6.6 \mathrm{~dB}$, which is higher than that achieved by the ordinary UWB antenna by more than $16 \%$. Comparison of the modified UWB antenna simulated and measured results shows a close agreement, which enable it to be a promising solution for many wireless applications such as UWB applications, X-band (8-12GHz) satellite communication, portable wireless devices, medical applications, positioning systems cognitive radio and WiMAX 5.4 GHz band application.
\end{abstract}

Keywords: Antenna, Enhanced gain, FR-4, UWB applications.

\section{Introduction}

Nowadays, with the rapid development in wireless communication systems, large bandwidth (in few GHz) with higher data rates is required. Microstrip antennas have the advantages of easy integration with microwave circuits, low cost, small size, and easy fabrication process [1]-[2]. Many microstrip antennas with various patch shape such as square, rectangular, triangular and circular have been proposed to improve the bandwidth into few $\mathrm{GHz}$ for UWB applications. Despite the abovementioned advantages of microstrip antennas, they suffer from short range bandwidth. Thus, many techniques have been applied to enhance the operating bandwidth. These techniques are meandered slots [3], defected ground structure (DGS) [4], excitation with coplanar waveguide technology [5, 6], elliptical patch [7], octagonal patch [8], circular [9] and modification in the ground plane shape [10].

Another technique applied to cope UWB applications is the design of monopole antennas with wide bandwidth as proposed in [11-15]. However, their gain is low. Many research works have been carried out on the ultrawideband (UWB) antennas since it was introduced by Federal Communication Commission which considers UWB band to have fractional bandwidth of $109.5 \%$ (from 3.1 to $10.6 \mathrm{GHz}$ ) [16]. Due to the advantages of planar UWB antennas such

*E-mail address: sharifagmed1113@gmail.com ISSN: 1791-2377 @ 2019 School of Science, IHU. All rights reserved. doi:10.25103/iestr.124.13 simpler structure, low cost and low profile [17], they were the most studied by researchers. However, these antennas suffer from poor radiation characteristics that limit use in many practical applications such as cognitive radios [18]-[19], portable wireless devices and positioning systems. Such wireless systems required a UWB antenna with high realized gain.

To overcome this above-mentioned issue, some methods to enhance the UWB antenna radiation characteristics have been reported. Electromagnetic band gap (EBG) loaded with UWB antennas [20] dielectric resonator [21] and stacked patches [22] techniques have been applied for UWB antenna gain enhancement. However, the adoption of parasitic elements into UWB antenna enlarges the physical size. Some designers have applied cavity-backed technique to increase the gain of UWB antenna as presented in [23-28]. Although the gain is enhanced, the antenna structure is quite bulky. In [29], modification to the patch and ground plane of UWB antenna is adopted to improve its impedance bandwidth. The antenna is fabricated using cost effective 4.4 permittivity FR4 substrate. This antenna can cover frequency range from $2.66 \mathrm{GHz}$ to $11 \mathrm{GHz}$. However, it's peak gain is limited to $3.157 \mathrm{~dB}$.

In this paper, a modified UWB antenna with wide range impedance bandwidth and high realized gain is proposed. This antenna uses circular patch with single microstrip feedline. The antenna is simulated and fabricated using lowcost FR-4 board. Slotting technique is adopted to modify the patch and ground plane of the proposed UWB antenna to enhance its realized gain to more than $6.5 \mathrm{~dB}$ maintaining a wide operating frequency ranging from 2.2 to more than 12 
$\mathrm{GHz}(138 \%)$. With this improvement, the proposed modified UWB antenna can be applied for many wireless applications, such as UWB applications, X-band $(8-12 \mathrm{GHz})$ satellite communication, portable wireless devices, medical applications WiMAX $5.4 \mathrm{GHz}$ band application, cognitive radios, portable wireless devices and positioning systems, efficiently.

\section{Geometry Design of UWB Antenna}

The modified UWB antenna proposed here consists of circular patch and single microstrip feedline as in the antenna front side in Fig. 1 (a). The slots etched in the radiated circular patch are designed to enhance the electric field radiation. Thus, realized gain is improved. Fig.1 (b) shows the UWB antenna backside where partial ground plane is designed. Two rectangular rings slots are designed in the ground plane, side to the feedline to improve the impedance matching. Calculation of UWB antenna dimensions is first conduced. The following are the formulas for circular patch microstrip antenna design. Then, the parameters are optimized using CST software. The optimized dimensions of modified UWB antenna are listed in Table 1. Circular patch radius is calculated using equation (1)-(2) [30].

$$
a=\frac{F}{\sqrt{1+\frac{2 h}{\pi \varepsilon_{r} F}}\left[\ln \left(\frac{\pi F}{2 h}\right)+1.77296\right]}
$$

Where, $a=$ Patch radius

$$
F=\frac{8.791 \times 10^{9}}{f_{r} \sqrt{\varepsilon_{r}}}
$$

$f_{r}=$ Resonant frequency

$h=$ Height of the dielectric substrate

$\varepsilon_{r}=$ Antenna substrate dielectric constant

Based on $50 \Omega$ Characteristic impedance, Wf and Lf of the microstrip feedline can be calculated using equations (3)(5) [30].

$$
\begin{aligned}
& Z_{o}=\frac{60}{\sqrt{\varepsilon_{\text {reff }}}} \ln \left(\frac{8 h}{W}+\frac{W}{4 h}\right) \text { for } \frac{W}{h}<1 \\
& Z_{o}=\frac{120 \pi}{\sqrt{\varepsilon_{\text {reff }}}\left[\frac{W}{h}+1.393+0.667 \ln \left(\frac{W}{h}+1.444\right)\right]} \\
& \text { for } \frac{W}{h}>1
\end{aligned}
$$

Where,

$\mathrm{W}=$ Feedline width

Effective dielectric constant, $\varepsilon_{\text {reff }}$

$$
\varepsilon_{\text {reff }}=\frac{\varepsilon_{r}+1}{3}+\frac{\varepsilon_{r}-1}{2} \frac{1}{\sqrt{\left(1+12 \frac{h}{W}\right)}}
$$

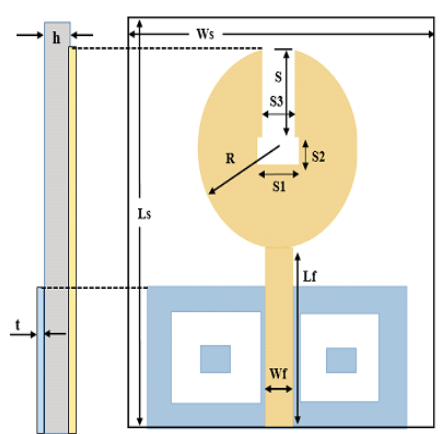

(a)

Fig. 1. Modified UWB antenna geometry. (a) Antenna front and side views, (b) Antenna back view.

Table 1. Modified UWB optimized parameters.

\begin{tabular}{c|c|c|c}
\hline Parameter & $\begin{array}{c}\text { Value } \\
{[\mathbf{m m}]}\end{array}$ & Parameter & $\begin{array}{c}\text { Value } \\
{[\mathbf{m m}]}\end{array}$ \\
\hline $\mathrm{Ws}$ & 55 & $\mathrm{~b}$ & 15 \\
$\mathrm{Ls}$ & 56 & $\mathrm{c}$ & 4 \\
$\mathrm{R}$ & 14.5 & $\mathrm{~d}$ & 5 \\
$\mathrm{Lf}$ & 20.6 & $\mathrm{~S}$ & 11.8 \\
$\mathrm{Wf}$ & 3 & $\mathrm{~S} 1$ & 7 \\
$\mathrm{Wg}$ & 50 & $\mathrm{~S} 2$ & 5 \\
$\mathrm{Lg}$ & 20 & $\mathrm{~S} 3$ & 5 \\
\hline $\mathrm{a}$ & 10 & \multicolumn{3}{|c}{ Null } \\
\hline
\end{tabular}

The antenna performance is influenced by the type of the substrate used. Substrate design parameters, such as loss tangent, substrate thickness and dielectric constant, effect the antenna characteristics. Substrate with low loss tangent and low dielectric constant values will have better performance as compared to those having higher values. In this work, FR4 substrate is used. FR-4 is known as the glass reinforced epoxy laminated sheets. FR-4 is a good choice as a substrate due to its low cost and its availability. Table 2 shows FR-4 board specifications.

Table 2. FR-4 substrate parameters

\begin{tabular}{l|l}
\hline Substrate Parameters & Value \\
\hline Dielectric constant, $\varepsilon_{\mathrm{r}}$ & 4.3 \\
Loss Tangent, $\delta$ & 0.019 \\
Conductor (copper) thickness, t & $0.035 \mathrm{~mm}$ \\
Substrate thickness, h & $1.6 \mathrm{~mm}$ \\
\hline
\end{tabular}

\section{Results and Discussion}

Modified UWB antenna simulated and measured results are illustrated in this section. Prior to fabrication process the antenna is simulated and optimized using simulation computer technology (CST).

\subsection{UWB Antenna Reflection Coefficient and Bandwidth} The proposed ultrawideband antenna is designed with micostrip feed line. The feed line width of the antenna is studied to have $50 \Omega$ characteristics impedance so that antenna can match with the coaxial cable during measurement process. The characteristic impedance is $49.43 \Omega$ which is closed to $50 \Omega$. The ultrawideband antenna reflection coefficient is presented in Fig. 2. It can be noted that the modified UWB antenna achieves $-10 \mathrm{~dB}$ impedance bandwidth from $1.8412 \mathrm{GHz}$ to more than $12 \mathrm{GHz}$, that is wider than the standard 
ultawideband antenna bandwidth that is between $3.1 \mathrm{GHz}$ to 10.6 GHz. The impedance bandwidth percentage can be calculated using equation (6) [30]. Based on this calculation, the proposed modified UWB antenna achieved an impedance bandwidth percentage of $138 \%$, which is wider than the standard UWB Band [16].

$$
B W=\frac{F_{H}-F_{L}}{\left(F_{H}+F_{L}\right) / 2}
$$

Where, $F_{H}$ represents the upper frequency and $F_{L}$ is the lower frquency.

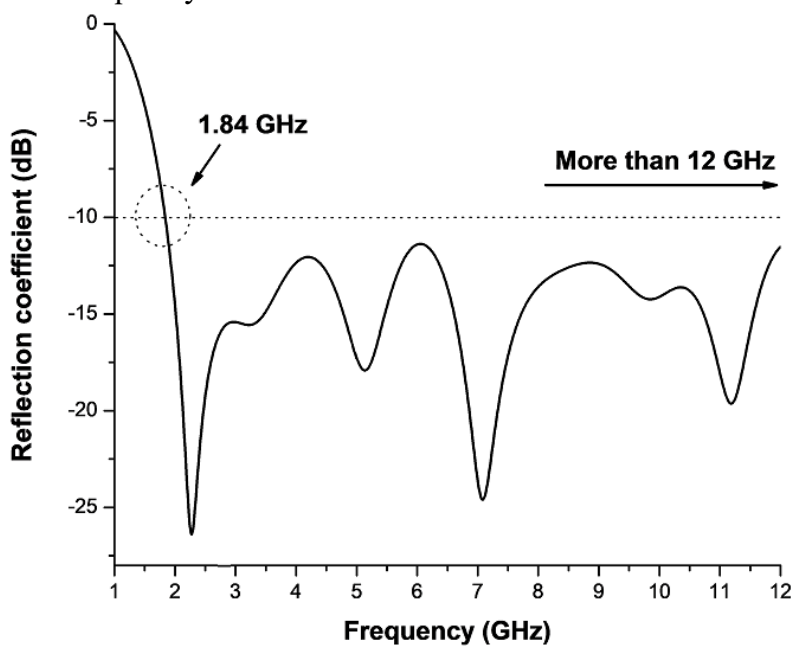

Fig. 2. Proposed ultrawideband antenna simulated reflection coefficient and bandwith.

\subsection{Ultrawideband Antenna Gain}

The antenna gains of the proposed modified UWB and ordinary UWB antenna are compared over a wide frequency range as shown in Fig. 3. The antenna with modified shape can achieve maximum gain of more than $6.5 \mathrm{~dB}$ at $8 \mathrm{GHz}$, whereas the maximum gain of the ordinary UWB antenna is limited to $5.5 \mathrm{~dB}$ at the same frequency. Thus, the embedded slots into the patch and ground plane has enhanced the UWB antenna gain. Gain of more than $3 \mathrm{~dB}$ is achieved at Wi MAX operating frequency $(5.4 \mathrm{GHz})$.

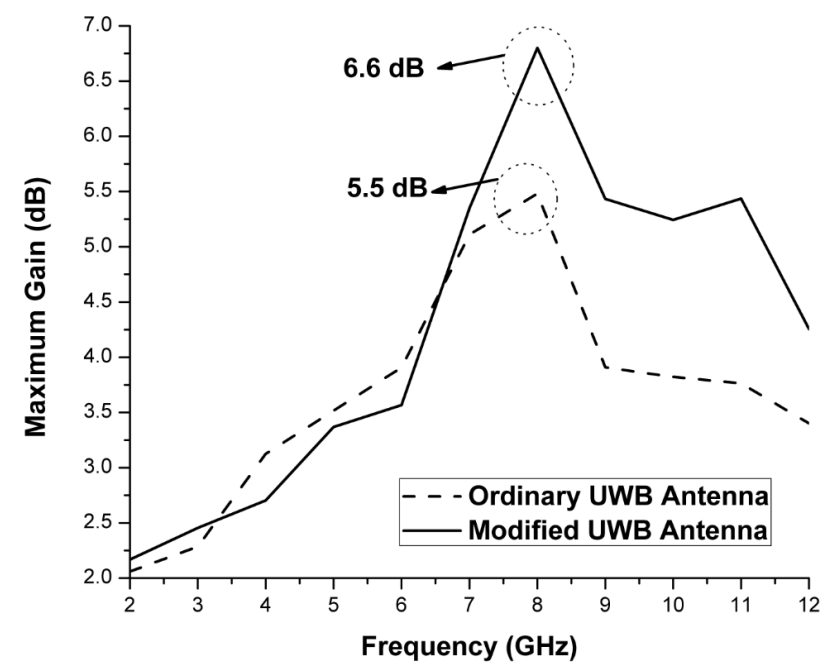

Fig. 3. Gains comparison of the modified UWB antenna and ordinary UWB antenna.

To investigate the effects of embedded slots into UWB antenna, surface current at $5 \mathrm{GHz}$ and $10 \mathrm{GHz}$ is studied. Fig. 4 (a) shows the surface current distribution density of the modified UWB antenna at $5 \mathrm{GHz}$, while Fig. 4 (b) shows the surface current distribution density at $10 \mathrm{GHz}$. Similarly, the surface current distribution density of the ordinary UWB antenna is simulated at $5 \mathrm{GHz}$ and $10 \mathrm{GHz}$ as presented in Fig. 5 (a) and Fig. 5 (b), respectively. From the current surface distribution view, it can be found that the current flow of the modified UWB antenna at $5 \mathrm{GHz}$ and $10 \mathrm{GHz}$ is stronger in comparison to the current flow of the ordinary UWB. This increases the antenna capacity and gain as well.

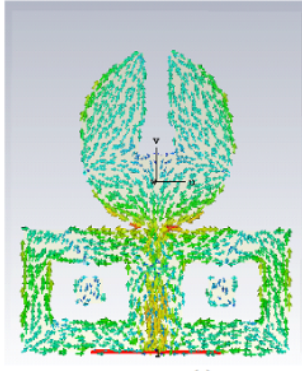

(a)

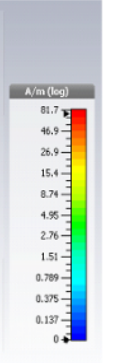

Fig. 4. Distributions of surface current of modified UWB antenna (a) at $5 \mathrm{GHz}$ and (b) at $10 \mathrm{GHz}$.
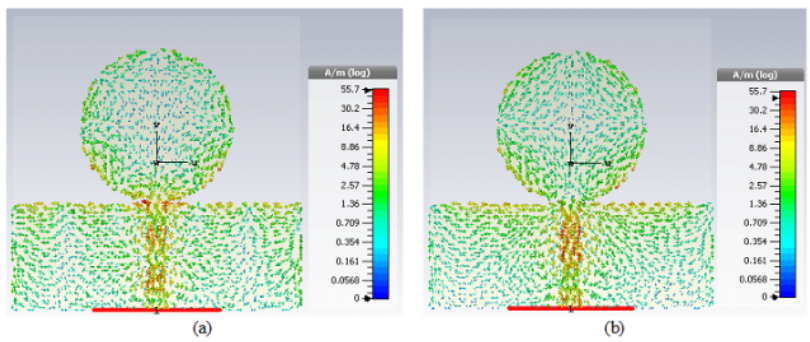

Fig. 5. Distributions of surface current of the ordinary UWB antenna (a) at $5 \mathrm{GHz}$ and (b) at $10 \mathrm{GHz}$.

\subsection{Fabricated Modified UWB Antenna}

Once the ultawideband antenna design characteristics are satisfactory, fabrication process took place in the laboratory. FR-4 substrate with 4.3 relative permittivity was used. The prototype of ultrawideband antenna is shown in Fig. 6. Fig. 6 (a) illustrates the ultrawideband antenna font view, while Fig. 6 (b) illustrates the back view of the modified ultawideband antenna. Small difference between simulated and measured results is due to manufacturing tolerance and soldering effects.
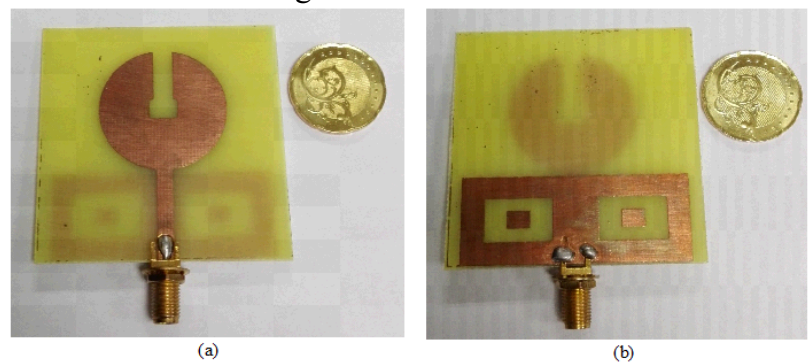

Fig. 6. Fabricated modified UWB antenna. (a) Prototype front view, (b) Protype back view

The measurement of modified UWB antenna is conducted in laboratory using Vector Network Analyzer (VNA). From the experimental results of the antenna, it is found that the $-10 \mathrm{~dB}$ operating bandwidth starts from 2.2 $\mathrm{GHz}$ to more than $12 \mathrm{GHz}$ as shown in Fig. 7. 


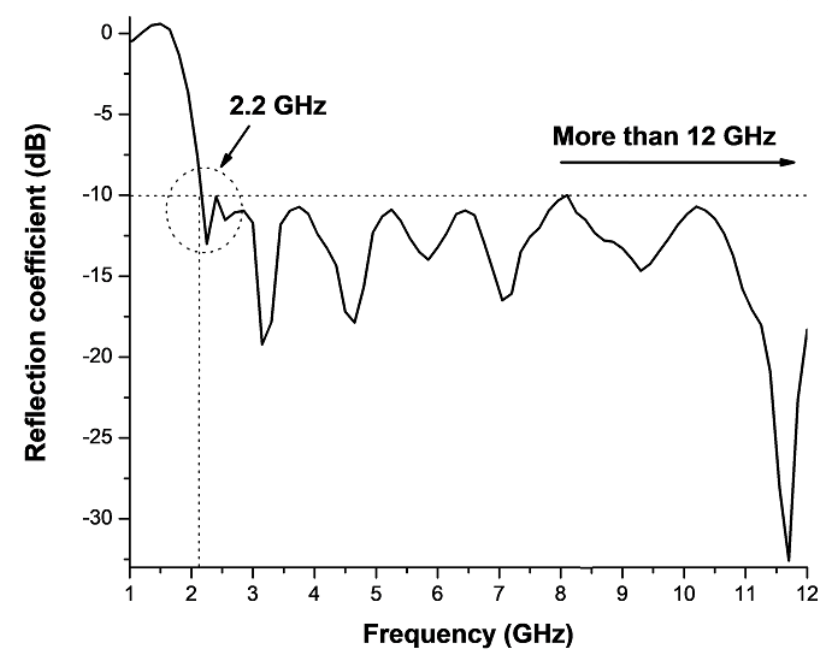

Fig. 7. Proposed ultrawideband antenna measured reflection coefficient and bandwidth

Comparison of the simulation and measurement results of modified UWB antenna is illustrated in Fig. 8 . It can be realized that the fabricated antenna maintains wide bandwidth excepts that the bandwidth starts at higher frequency compared to the simulated results. This shift is due to the permittivity tolerance variation of FR-4 board.

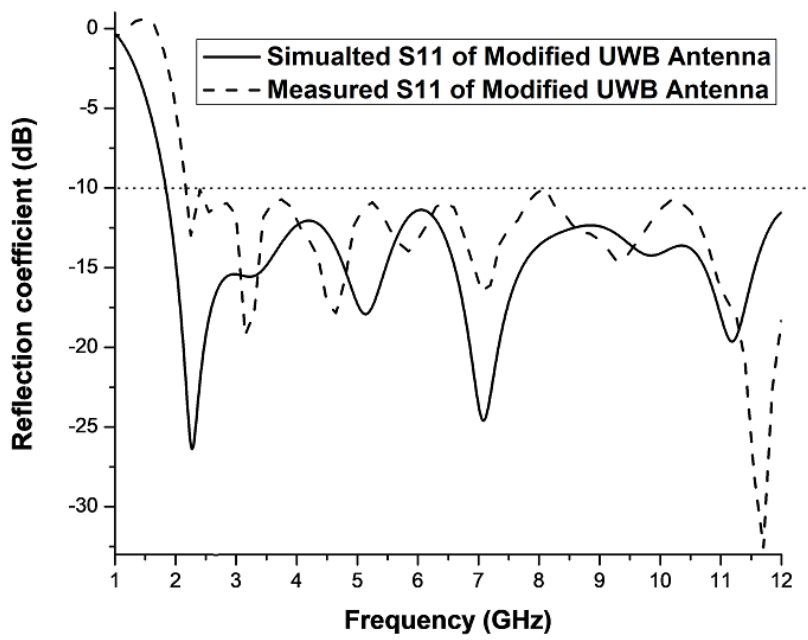

Fig 8. Simulated and measured reflection coefficient and bandwidth of modified UWB antenna.

Table 3 shows a comparison between past studies on UWB antennas and the proposed UWB antenna related to impedance bandwidth, peak gain achieved and type of substrate used.

Table 3. Comparison between the past studies and proposed UWB antenna

\begin{tabular}{|c|c|c|c|c|c|}
\hline $\begin{array}{l}\text { Past studies on } \\
\text { UWB antenna }\end{array}$ & $\begin{array}{l}\text { Impedance bandwidth } \\
\text { range }(\mathrm{GHz})\end{array}$ & $\begin{array}{c}\text { Bandwidth } \\
(\%)\end{array}$ & $\begin{array}{l}\text { Bandwidth } \\
\text { (GHz) at } \\
\text { VSWR }<2\end{array}$ & $\begin{array}{l}\text { Peak gain } \\
\text { (dB) }\end{array}$ & $\begin{array}{l}\text { Type of substrate } \\
\text { used }\end{array}$ \\
\hline [29] & 2.66 to 11 & 122.1 & 8.34 & 3.157 & FR-4 \\
\hline [31] & 3.1 to 13 & 122.9 & 9.9 & $\sim 6$ & $\begin{array}{c}\text { Rogers RT/duroid } \\
5880\end{array}$ \\
\hline$[32]$ & 2.5 to 10.8 & 124.81 & 8.3 & $\sim 3.8$ & FR-4 \\
\hline [33] & 3.1 to 10.6 & 109.48 & 7.5 & 5.7 & FR-4 \\
\hline [34] & 3.1 to more than 11 & 112.05 & 7.9 & $\sim 4$ & Taconic \\
\hline [35]. & 3.1 to 10.6 & 109.48 & 7.5 & $\sim 4.5$ & FR-4 \\
\hline$[36]$ & 2.6 to more than 15 & $<141$ & 12.4 & $\sim 4$ & FR-4 \\
\hline [37] & 3.0 to 14 & 129.4 & 11 & 5.3 & $\begin{array}{c}\text { Rogers RT/duroid } \\
5880\end{array}$ \\
\hline [38] & 2.78 to 12.8 & 128.6 & 10.02 & $\sim 3.92$ & FR-4 \\
\hline This work & 2.2 to more than 12 & $<138$ & $<9.8$ & 6.5 & FR-4 \\
\hline
\end{tabular}

\section{Conclusion}

A new modified circular shape UWB antenna has been reported. The modification of the radiated patch and the partial ground plane has achieved wide impedance bandwidth as well as high realized gain. This UWB antenna can provide $-10 \mathrm{~dB}$ bandwidth ranging from 2.2 to more than $12 \mathrm{GHz}$, that is equal to $138 \%$ fractional bandwidth. In addition to that, the modified UWB antenna has a maximum gain of more than $6.5 \mathrm{~dB}$. The high performance of the modified UWB antenna with the close similarity between simulation and measurement results enable it to be a good choice for wireless application such as UWB applications, cognitive radio, WiMAX $5.4 \mathrm{GHz}$ band application, positioning systems MVDDS (12.2$12.7 \mathrm{GHz})$ band application, and X-band $(8-12 \mathrm{GHz})$ satellite communication and portable wireless devices and medical applications. As this work focus on single element of UWB antenna, array of UWB antennas can be considered for future work. Besides that, more efficient substrate such Roger boards can be used to further enhance the performance of UWB antennas.

\section{Acknowledgements}

Authors would like to thank funding bodies under project of "Mobile IOT: Location Aware" (grant no. MMUE/180025) and project of "Indoor Internet of Things (IOT) Tracking Algorithm Development based on Radio Signal Characterisation" (grant no. FRGS/1/2018/TK08/MMU/02/1).

This is an Open Access article distributed under the terms of the Creative Commons Attribution License 


\section{References}

1. G. Kumar, K P. Ray, "Broadband Microstrip Antennas," Artech House, USA. 2003

2. M K. Shrivastava A K. Gautam, B K. A. Kanaujia, "novel a-shaped monopole-like slot antenna for ultrawideband applications. Microwave and Optical Technology Letters, vol. 56, no. 8, pp. 1826-1829, 2014

3. M E. Bialkowski, A M. Abbosh, "Design of UWB Planar Antenna with Improved Cut-Off at the Out- of-Band Frequencies," IEEE Antennas and Wireless Propagation Letters. vol. 7, pp. 408-410, 2008.

4. M. Challal, A. Azrar, M. Dehmas, "Rectangular patch antenna performances improvement employing slotted rectangular shaped for WLAN applications," International journal of computer science Issues. vol. 8, no. 3, pp. 254 258, 2011.

5. A K. Gautam, S. Yadav, B. K. Kanaujia, "A CPW- FED compact inverted L-strip UWB microstrip antenna. Microwave and Optical Technology Letters. vol. 55, no. 7, pp. 1584-1589, 2013

6. Y. Li, W. Li, R. A. Mittra, "compact CPW-fed circular slot antenna with reconfigurable dual band notch characteristics for UWB communication applications," Microwave and Optical Technology Letters. vol. 56, no. 2, pp. 465-468. 2014.

7. G S. Reddy, S K. Mishra, S. Kharche, "High gain and low crosspolar compact printed elliptical monopole UWB antenna loaded with partial ground and parasitic patches," Progress In Electromagnetics Research B. vol. 43, pp. 151-167, 2012.

8. M. Bitchikh, A. Azrar, R. Aksas, "UWB Coplanar Waveguide Octagonal Antenna," Wireless Personal Communications, pp. 1$8,2015$.

9. J. Liang, C C. Chiau, X. Chen, "Study of a printed circular disc monopole antenna for UWB systems," IEEE Transactions on Antennas and Propagation, vol. 53, no. 11, pp. 3500-3504, 2005.

10. H. Kimouche, D. Abed, B. Atrouz, "Investigation on microstrip-fed modified elliptical monopole antenna for UWB communications," European Conference on Antennas and Propagation, 2009.

11. J Y. Sze, C I G. Hsu, C H. Lin, "Compact broadband circularly polarized monopole antenna," International Symposium on Antennas and Propagation (ISAP). pp. 611-612, December 2014.

12. L. Wang, S. Lin, R N. Cai, G L, Huang W B. Zhang, "Multiband printed monopole antenna with squarenested fractal," 6th International Conference on Communications and Networking in China (CHINACOM), pp.929-932, August 2011.

13. H. Fallahi, Z. Study of a class of UWB CPW-fed monopole antenna with fractal elements. IEEE Antennas and Wireless Propagation Letters. 2013; vol.12, pp.1484-1487.

14. M N, Iqbal, H U. Rahman, S F. Jilani, "Novel compact wide band coplanar waveguide fed heptagonal fractal monopole antenna for wireless application," 14th annual IEEE Wireless and Microwave Technology Conference (WAMICON), pp.1-3, April 2013.

15. R. Pillalamarri, J R. Panda, R S. Kshetrimayum, "Printed UWB circular and modified circular disc monopole antenna," International Journal of Recent Trends in Engineering issue 1. vol.1, May 2009

16. Federal Communications Commission, Revision of Part 15 of the Commission's Rules Regarding Ultra-Wideband Transmission System From 3.1 to

10.6 GHz. Washington, D.C., USA: Federal Communications Commission, pp. 98-153, 2002.

17.G. Adamiuk, T. Zwick, W. Wiesbeck, "UWB antennas for communication systems," Proceeding of the IEEE. vol. 100, no. 7, pp. 2308-2321, July 2012.

18. F. Fereidoony, S. Chamaani, S A. Mirtaheri, "UWB monopole antenna with stable radiation pattern and low transient distortion," IEEE Antennas Wireless Propag. Letter, vol. 10, pp. 302-305, Apr. 2011.

19. G K. Pandey, H S. Singh, P K. Bharti, M. K, Meshram, "UWB monopole antenna with enhanced gain and stable radiation pattern using gate like structures," in Proc. Int. Conf. Microw. Photon. (ICMAP'13), pp. 1-4, 2013.

20. R. Boopathi Rani, S K. Pandey, "A CPW-Fed Circular Patch Antenna Inspired by Reduced Ground Plane and CSRR Slot for
UWB Applications with Notch Band," Microwave and Optical Technology Letters. vol. 59, 2017.

21. K S. Ryu, A. A. Kishk, "UWB dielectric resonator antenna having consistent omnidirectional pattern and low cross-polarization characteristics," IEEE Transaction Antennas Propagation, vol. 59, no. 4, pp. 1403-1408, April 2011.

22. W. A. Zhang, C. Hoorfar Thajudeen, "Boresight gain enhancement of an UWB planar monopole antenna," in Proc. IEEE. Soc. International Symposium on Antennas Propagation. (APSURSI'12), pp. 1-2, 2012.

23. J K. Paek, H J. Eom, "Cylindrical Cavity-Backed Antenna," in IEEE Antennas Propagation. Letter, vol. 8, pp. 852-855, 2009.

24. M H. Awida, Elkhouly, E. Fathy, "Low-Cost High- Efficiency Substrate-Integrated Cavity-Backed Single Element Antenna," in IEEE Antennas Propagation. Society Int. Symp., pp. 10-13, 2010.

25. A. Nesic, I, Radnovic, N. Vojnovic, "New Type of Cavity-Backed Antenna with Circular Polarization," in 10th Int. Conf. Telecomm. modern satellite and cable Broadcasting services. pp. 407-410, 2011.

26. Li, Mingjian, and K. Luk, "A Differentially-fed Magneto-Electric Dipole Antenna for UWB Applications," in Asia-Pacific Microw. Conf. Proc. pp.1953-1956, 2011.

27. R.A Moddy, S K. Sharma, "Ultra-wide Bandwidth (UWB) Planar Monopole Antenna Backed by Novel Pyramidal-Shaped Cavity Providing Directional Radiation Patterns," in IEEE Antennas Wireless Propagation Letter. pp.1469-1472, 2011.

28. S. Qu, C. Chan, Q. Xue, "Ultra-wide band composite cavitybacked folded sectorial antenna with stable pattern and high gain," in IEEE Transaction Antennas Propagation. vol. 57, no. 8 , pp. 2478-2483, 2009.

29. N. Anveshkumar, A S. Gandhi, "Design and performance analysis of a modified circular planar monopole UWB antenna," In IEEE 8th International Conference on Computing, Communication and Networking Technologies (ICCCNT). pp. 1$5,2017$.

30. B. J. Kwaha, O. N. Inyang, P. Amalu, "The circular microstrip patch antenna-design and implementation," International Journal of Recent Research and Applied Studies (IJRRAS), 8 (1), pp. 8695, July 2011.

31. H. Oraizi, N. Valizade Shahmirzadi, "Frequency- and timedomain analysis of a novel UWB reconfigurable microstrip slot antenna with switchable notched bands," IET Microwaves, Antennas Propagation. vol. 11, no. 8, 1127-1132, 2017.

32. M Moosazadeh, A M. Abbosh, Z. Esmati, "Design of compact planar ultrawideband antenna with dual- notched bands using slotted square patch and pi- shaped conductor-backed plane. IET Microwaves Antennas Propagation, Vol. 54, No. 9, 2053-2056, 2012.

33. M N Srifi, S K Podilchak, M Antar, Y M M Essaaidi, "Compact disc monopole antennas for current and future ultrawideband (UWB) applications," IEEE Transaction Antennas Propagation, Vol. 59, No. 12, 4470-4480, 2011.

34. J Y Siddiqui, C Saha, Y M. Antar, "Compact dual- SRR-loaded UWB monopole antenna with dual frequency and

wideband notch characteristics," IEEE antennas and wireless propagation letters. 14. 100-103, 2015.

35. A. Saxena, R P S. Gangwar, "A compact UWB antenna with dual band-notched at WiMAX and WLAN for UWB applications," Int. Conf. Electr. Electron. Optim. Tech., 4381-4386, 2016.

36. S R Emadian, J. Ahmadi-Shokouh, "Very small dual bandnotched rectangular slot antenna with enhanced impedance bandwidth," IEEE Transaction Antennas Propagation, Vol. 63, No. 10, 4529-4534, 2015

37. A. Alhegazi, Z. Zakaria, N. A. Shairi, I M Ibrahim, S. Ahmed, "A Novel Reconfigurable UWB Filtering-Antenna with Dual Sharp Band Notches Using Double Split Ring Resonators," Progress In Electromagnetics Research, 79. 185-198, 2017.

38. A. Kumar, I. B. Sharma, M. M. Sharma "Reconfigurable circular disc monopole UWB antenna with switchable two notched stop bands," IEEE India Council International Conference (INDICON).; 2-5, 2016 